\title{
INCLUSÃO EM EDUCAÇÃO: desafios do público-alvo da educação especial na educação profissional
}

\author{
Maria Leilza Pires Siqueira \\ Patricia Ferreira de Andrade \\ Allan Rocha Damasceno
}

\section{Resumo}

Essa pesquisa objetivou caracterizar as concepções e ações político-pedagógicas sobre a inclusão em educação do público-alvo da educação especial na educação profissional técnica do Instituto Federal de Educação, Ciência e Tecnologia de Roraima (IFRR) - Campus Boa Vista (CBV). Assim, essa pesquisa teve como investigação central analisar as políticas públicas de inclusão em educação, buscando compreender os desafios à escolarização profissional desse público pertencente à educação profissional. Esse estudo fundamentou-se na Teoria Crítica da educação com ênfase ao pensamento de Theodor Adorno. Quanto aos instrumentos e procedimentos metodológicos de pesquisa, realizamos entrevistas semiestruturadas com os sujeitos participantes do estudo e também aplicamos questionário de caracterização com esses participantes da pesquisa. Foram entrevistados sete gestores que contribuíram com a pesquisa na identificação das concepções e ações político-pedagógicas/inclusivas. Constatou-se que há iniciativas no Campus de ações inclusivas, porém a pesquisa revelou barreiras que obstaculizam a implementação da educação especial na perspectiva inclusiva.

Palavras-chave: políticas públicas; educação especial; educação profissional.

INCLUSION IN EDUCATION: challenges of the target audience of special education in professional education

\begin{abstract}
This research aimed to characterize the political-pedagogical conceptions and actions on the inclusion in education of the target audience of special education in technical professional education of the Federal Institute of Education, Science and Technology of Roraima (IFRR) - Campus Boa Vista (CBV). Thus, this research had as its central investigation, to study the public policies of inclusion in education, seeking to understand the challenges to professional education of this public belonging to Professional Education. This study was based on the Critical Theory of education with emphasis on Theodor Adorno's thinking. The following research procedures were adopted: questionnaire to characterize the subjects participating in the study and semi-structured interview. Seven managers were interviewed who contributed to the research in the identification of political-pedagogical / inclusive conceptions and actions. It was found that there are initiatives in the Campus of inclusive actions, however the research revealed barriers that hinder the implementation of special education in the inclusive perspective.
\end{abstract}

Keywords: public policy; special education; professional education. 
DOI: $10.12957 /$ teias.\%Y.50871

INCLUSIÓN EL LA EDUCACIÓN:

desafíos del público objetivo de educación especial en educación profesional

Resumen

Esta investigación tuvo como objetivo caracterizar las concepciones y acciones político-pedagógicas sobre la inclusión en la educación del público objetivo de educación especial en educación técnica profesional del Instituto Federal de Educación, Ciencia y Tecnología de Roraima (IFRR) - Campus Boa Vista (CBV). Por lo tanto, esta investigación tuvo como investigación central, estudiar las políticas públicas de inclusión en la educación, buscando comprender los desafíos para la educación profesional de este público perteneciente a la educación profesional. Este estudio se basó en la teoría crítica de la educación con énfasis en el pensamiento de Theodor Adorno. Se adoptaron los siguientes procedimientos de investigación: cuestionario para caracterizar a los sujetos que participaron en el estudio y entrevista semiestructurada. Se entrevistó a siete gerentes que contribuyeron a la investigación en la identificación de concepciones y acciones político-pedagógicas / inclusivas. Se encontró que hay iniciativas en el Campus de acciones inclusivas, sin embargo, la investigación reveló barreras que obstaculizan la implementación de educación especial en la perspectiva inclusiva.

Palabras clave: política pública; educación especial; educación profesional

\section{INTRODUÇÃO}

A problemática abordada nesse estudo se refere às políticas públicas de inclusão em educação e seu desafio quanto à implementação na escolarização profissional dos estudantes pertencentes a outra modalidade de ensino: a educação especial. Essa pesquisa objetivou caracterizar as concepções e ações político-pedagógicas sobre a inclusão em educação do públicoalvo da educação especial na educação profissional técnica do Instituto Federal de Educação, Ciência e Tecnologia de Roraima (IFRR) - Campus Boa Vista (CBV).

É importante salientar que, de acordo com a Política Nacional de Educação Especial na perspectiva da Educação Inclusiva (2008), o público-alvo da educação especial no Brasil é composto pelos alunos com deficiências, transtornos globais do desenvolvimento (TGD) e altas habilidades/superdotação. Os institutos federais de educação possuem o objetivo de profissionalizar a todos os estudantes, e os estudantes pertencentes à modalidade da educação especial também possuem esse direito. Conforme Pacheco (2011), os institutos federais devem, ao construir sua proposta pedagógica, fazê-lo com:

[...] a propriedade que a sociedade está a exigir e se transformem em instrumentos sintonizados com as demandas sociais, econômicas e culturais, permeando-se das questões de diversidade cultural e de preservação ambiental, o que estará a traduzir um compromisso pautado na ética da responsabilidade e do cuidado (p. 25).

Nesse sentido, o Instituto Federal de Educação, Ciência e Tecnologia de Roraima IFRR, cenário dessa pesquisa, define como Política de Ensino Técnico, que: "[...] a Educação Profissional deve articular, sob a perspectiva da totalidade, síntese de múltiplas relações, sem dicotomia entre conhecimentos gerais e específicos, valorizando os conceitos: trabalho, cultura, ciência e tecnologia" (PDI, 2019-2023, p. 82).

Muitos desafios foram superados até chegar ao cenário que se apresenta hoje em relação à pessoa com deficiência. A década de 1990 se configura como divisor de águas para a educação como um todo, pois, a partir desse momento, os sistemas de ensino passaram a desenvolver 
políticas públicas de inclusão, trabalhando para minimizar a discriminação, numa perspectiva de democratizar a educação.

A escolarização dos estudantes público-alvo da educação especial tem sido um desafio em todos os níveis e modalidades de ensino. Podemos citar como um desses desafios a escassez de profissionais capacitados para atender esses estudantes nos institutos.

A instituição pesquisada, por meio do NAPNE (Núcleo de Atendimento às Pessoas com Necessidades Educacionais Específicas), tem buscado parceria com profissionais de áreas distintas para auxiliar o estudante pertencente ao público-alvo da Educação Especial. Contudo, há muito a se discutir sobre a democratização do conhecimento nos sistemas de ensino, como disse Pietro:

\begin{abstract}
As instituições escolares, ao reproduzirem constantemente o modelo tradicional, não têm demonstrado condições de responder aos desafios da inclusão social e do acolhimento às diferenças, nem de promover aprendizagens necessárias à vida em sociedade, particularmente nas sociedades complexas do século XXI (PIETRO, 2006, p. 33).
\end{abstract}

Diante disso, os professores são provocados a assumir o papel de protagonistas, elaborando e implementando novas propostas e práticas para responder às demandas de ensino e aprendizagem dos estudantes, independentemente de etapas ou modalidades de ensino: "[...] Novos tempos requerem nova qualidade educativa, o que implica mudança nos currículos, na gestão educacional, na avaliação dos sistemas e na profissionalização dos professores" (LIBÂNEO, OLIVEIRA, TOSCHI, 2012, p.43).

Nesse contexto, todos precisam afirmar o compromisso com a inclusão em educação, adaptando-se aos variados ritmos e estilos de aprendizagens de cada estudante, a fim de que possam adquirir autonomia com vistas ao seu desenvolvimento pleno, pois "[...] diferentes elementos históricos podem sustentar que, definitivamente, a educação escolar básica, pública, laica, universal, unitária e tecnológica, nunca se colocou como necessidade e sim como algo a conter para a classe dominante brasileira” (FRIGOTTO, 2007, p. 7).

Percebe-se que o projeto de educação desenhado no Brasil sempre caminhou para o favorecimento e perpetuação da classe dominante, impedindo que a classe trabalhadora alcançasse sua emancipação. Desse modo, "[...] a divergência persiste entre a cidade e o campo, a não formação cultural do agrário, cujas tradições são declinantes e irrecuperáveis, é uma das figuras em que a barbárie se perpetua" (ADORNO, 1995, p. 67).

Atualmente, a educação técnica profissional nos IFs é ofertada em instituições públicas de todo o país. É visualizada como uma modalidade de ensino que tomou grandes proporções, pois seus 644 campi estão espalhados em todos os estados da federação brasileira, buscando atender o jovem de norte a sul do país. A implantação dos campi gera a grande expectativa e esperança na população de que, a partir da conclusão do curso em uma dessas instituições, o jovem possa entrar no mundo do trabalho, com qualificação para competir e disputar uma vaga, exercer uma profissão. 
DOI: $10.12957 /$ teias.\%Y.50871

\section{OLHARES PLURAIS NA/PARA A DIFERENÇA: PASSOS DA PESQUISA}

Essa pesquisa fundamentou-se na Teoria Crítica, com ênfase ao pensamento de Theodor Adorno, filósofo alemão que problematiza a sociedade de classes e permite pensar uma educação emancipada para além da adaptação.

Considerando a educação e a escola num contexto de superação de estigmas construídos por uma sociedade alienada, fruto de uma educação opressora e discriminatória, Adorno (1995, p. 116) afirma que "[...] não se deve esquecer que a chave da transformação decisiva reside na sociedade e na sua relação com a escola".

Nesse estudo, foram adotados os seguintes procedimentos de pesquisa: questionário de caracterização dos participantes, entrevistas semiestruturada e análise documental.

Para traçar o perfil dos sujeitos participantes, foi realizado um questionário de caracterização com as seguintes dimensões investigadas: identificação, formação acadêmica, titulação máxima, tempo de serviço na instituição, tempo em que ocupava o cargo, função/cargo, participação em eventos voltados para o público-alvo da educação especial.

Os sujeitos/participantes foram sete servidores do Campus pesquisado, ocupantes de cargos de gestão. Para proteger suas identidades optou-se por numerá-los de um a sete, ficando assim: P1; P2; P3; P4; P5; P6; P7.

Dos sete gestores participantes, quatro são licenciados e três são bacharéis, $71,4 \%$ estão no cargo atual há média de dois anos, 57,1\% têm espacialização; 42,9\% têm mestrado. Contribuíram com essa pesquisa três ocupantes de cargo de Diretor e quatro ocupantes de cargo de Coordenação.

O objetivo do questionário foi caracterizar os sujeitos da pesquisa, que responderam por escrito, de forma objetiva e sistematizada. Conforme Severino (2007), as questões devem ser objetivas, de modo a suscitar respostas igualmente objetivas, evitando provocar dúvidas, ambiguidades e respostas lacônicas. Assim, foi posto em ação o questionário.

As entrevistas tinham como enfoque tratar sobre a inclusão em educação dos estudantes público-alvo da educação especial na educação profissional, bem como das políticas institucionais de inclusão e o papel do NAPNE (Núcleo de Atendimento às Pessoas com Necessidades Educacionais Específicas) no IFRR, Campus Boa Vista. Seguiu-se um roteiro semiestruturado com três blocos de perguntas com cinco questões cada: cinco sobre educação especial na perspectiva inclusiva; cinco sobre políticas institucionais de inclusão do público-alvo da educação especial no IFRR/Campus Boa Vista, e cinco sobre a inclusão do público-alvo da educação especial na educação profissional: papel do NAPNE no IFRR/Campus Boa Vista.

Após a conclusão das entrevistas, foram realizadas as transcrições, as quais foram feitas na íntegra, logo após cada entrevista, visando não perder nenhuma informação, fosse ela explícita ou implícita. A transcrição resultou num trabalho de 64 páginas.

Quanto à análise de documentos institucionais, essa pesquisa se deteve em analisar documentos como o Plano de Desenvolvimento Institucional (PDI), Organização Didática e Projetos de Cursos Técnicos do IFRR.

As entrevistas foram analisadas a partir de três eixos: a) inclusão em educação; b) políticas institucionais de inclusão do público-alvo da educação especial no IFRR, Campus Boa Vista e; c) inclusão do público-alvo da educação especial na educação profissional: papel do NAPNE no IFRR/CBV. 
DOI: $10.12957 /$ teias. $\%$ Y.50871

\title{
EDUCAÇÃO ESPECIAL E EDUCAÇÃO PROFISSIONAL: REFLETINDO A INCLUSÃO EM EDUCAÇÃO NO CAMPUS BOA VISTA
}

O Plano de Desenvolvimento Institucional (PDI) do IFRR trata-se de um documento que identifica a instituição no que diz respeito ao seu papel social, que orienta suas ações quanto à estrutura organizacional e às atividades acadêmicas que desenvolve. A análise desse documento foi realizada considerando o momento atual da instituição, numa perspectiva de procurar observar as diretrizes pensadas para o atendimento do público-alvo da educação especial na educação profissional.

Uma das estratégias do IFRR é criar condições para atender às demandas das Pessoas com Necessidades Educacionais Específicas (PNEEs) centrando-se nas condições físicas e pedagógicas. Essa proposta é fundamentada na Organização Didática/IFRR no Art. $9^{\circ}$, capítulo II: "Projetos Pedagógicos de Cursos deverão contemplar princípios inclusivos nas propostas curriculares de seus cursos, garantindo ações voltadas ao respeito, às diferenças e a diversidade humana". Especifica ainda, no inciso II, que:

\begin{abstract}
A inclusão mencionada refere-se a responsabilidades concernentes no atendimento aos estudantes com necessidades específicas, tais como: equipamentos e recursos didáticopedagógicos, acessibilidade de informação e comunicação, adaptação do espaço físico e virtual e pessoal docente e técnico qualificado (ORGANIZAÇÃO DIDÁTICA 2019-2023, p. 9).
\end{abstract}

Os documentos propõem políticas de inclusão em educação contemplando acessibilidade arquitetônica, de comunicação, metodológica, atitudinal e programática, fundamentando assim a tríade: acesso, permanência e êxito educacional.

O IFRR estimula a permanência e o êxito educacional aos estudantes no que se refere à aprendizagem educacional com as seguintes ações:

- Trabalhos em grupos e individuais, pesquisas, experimentos, desenvolvimento de projetos a partir de situações problema.

- Atividades esportivas e culturais;

- Projeto de fortalecimento dos Núcleos de Atendimento às Pessoas com Necessidades Educacionais Específicas (Napnes);

- Apoio a projetos de pesquisa e extensão; acesso a laboratórios e bibliotecas equipados com recursos multimídias, e;

- Encaminhamento ao mundo de trabalho por meio da integração escolaempresa-comunidade. (PDI, 2019-2023, p. 134)

O Instituto Federal de Roraima, Campus Boa Vista, cenário desta pesquisa, atende 3.157 estudantes nos diversos níveis e modalidades.

Desse total, 45 são estudantes público-alvo da educação especial, doze estão nos cursos técnicos profissionalizantes integrados ao ensino médio e, apenas dez estão com matrículas ativas. O gráfico a seguir, na Figura 1, apresenta o cenário das deficiências. 


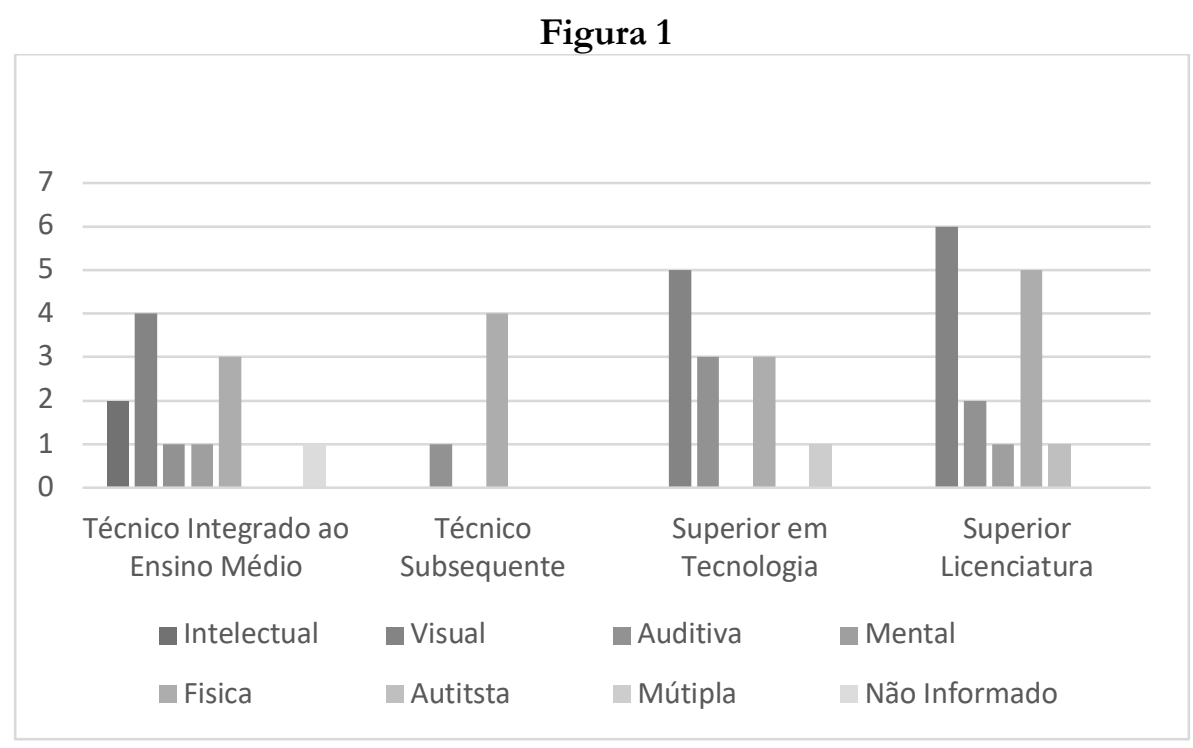

Gráfico de elaboração própria a partir da Fonte: NAPNE/CBV

A Lei Brasileira de Inclusão (2015) define pessoa com deficiência aquela que tem impedimentos de longo prazo de natureza física, mental, intelectual ou sensorial. Assim, para a participação plena e efetiva desses sujeitos, tanto na escola como na sociedade, torna-se indispensável condições que acolham suas especificidades, garantindo a participação plena desse sujeito/estudante.

Os participantes compreendem que, além de um direito para quem tem deficiência, as concepções de inclusão em educação também são para os que estão excluídos nos aspectos social, educacional, por questão de raça, cor ou religião. Assim como para aqueles que não se enquadram em nenhum desses aspectos, mas precisam se incluir nesse processo, respeitando as limitações de cada um e colaborando para uma sociedade mais humana e solidária.

Tomazi (2013) nos explica que:

A educação do novo milênio precisa rever profundamente qual seria o papel de cada um dentro da coletividade de maneira geral, preparar para vencer e recriar a estrutura social e não para viver nela e segundo ela, reinventando, inclusive, o conceito de bemsucedido. (p. 50).

Dessa maneira, é relevante que essas mudanças comecem na base da educação, para colaborar com o que um dos participantes chama de "[...] histórico de descaso, mesmo, que eles tiveram na época que eles estavam nas suas etapas de educação fundamental, do fundamental 1 , fundamental 2" (P7).

P7 se refere às dificuldades apresentadas pelos estudantes público-alvo da educação especial quando chegam ao ensino médio. é preciso ofertar um ensino básico de qualidade respeitando a diversidade que se encontra no âmbito escolar.

A Lei de Diretrizes e Bases da Educação Nacional, Lei 9.394/96 no artigo 59, afirma que os sistemas de ensino devem assegurar aos estudantes currículo, métodos, recursos e organização específicos para atender às suas necessidades.

A política que dispõe sobre a Educação Especial e Atendimento Educacional Especializado, o Decreto 6.711/2011 em seu Art. 1º preconiza que: “[...] considera-se público- 
DOI: $10.12957 /$ teias. $\%$ Y.50871

alvo da educação especial as pessoas com deficiência, com transtornos globais do desenvolvimento e com altas habilidades ou superdotação". Questionados sobre o entendimento do AEE para um público específico, um participante respondeu:

[...] Se a gente não tivesse esses encaminhamentos legais, acredito que aí mesmo é que não seriam atendidos, porque se posto em lei que tem que ser feito, que tem que ser atendido, muitas vezes o aluno tem que brigar na justiça (P1).

Essa ainda é uma realidade: ver estudantes terem que recorrer pelas vias legais o direito de estudar, ou mesmo, quando conseguem o acesso, precisam lutar na Justiça pelo direito ao AEE, porque muitas escolas públicas não provêm dos recursos necessários para o atendimento.

Para os participantes desta pesquisa, o desafio da inclusão em educação está em dialogar sobre o tema dentro da instituição:

[...] então, a gente vê que embora não sejam tão recentes essas discussões, o desafio maior é manter uma constância de discussão, de diálogos, de capacitação sobre inclusão, sobre educação inclusiva e de fato praticar (P2).

[...] acredito que essas políticas precisam de fato se fazer presente nas instituições. Isso porque nós vemos pouco, principalmente políticas que venham para trabalhar com os professores. Isso porque ainda falta muito trabalho com os docentes para que eles possam fazer flexibilização de conteúdo, para vários tipos de deficiência. Então, assim, as políticas, elas são necessárias, importantes (P 5).

Conseguir a adesão de todos para a luta da inclusão em educação não é tarefa fácil. Em vários momentos os gestores colocam essa dificuldade: trazer para o debate o corpo docente. É preciso a mobilização de todos para o processo de inclusão em educação, pois não se faz inclusão com grupos isolados. Essas foram questões assinaladas como maior dificuldade na inclusão em educação, no que tange ao atendimento do grupo pertencente à educação especial no Campus Boa Vista.

Nas entrevistas com os participantes, observou-se o relato de que os docentes não apoiam a inclusão. Os sujeitos da pesquisa descrevem que a justificativa dos professores é de que, por exemplo: em deficiências como a visual não é possível manter o estudante em alguns cursos técnicos tais como: enfermagem, eletrotécnica, entre outros.

A escola tradicional homogênea foi superada por uma escola aberta a todos. Adorno (1995) afirma que é preciso desbarbarizar. Isso implica em mudança de postura. Não podemos continuar com o discurso de que "isso não é problema meu". Nesse contexto, a resistência das pessoas em aceitar a mudança pode provocar o que Adorno chama de barbárie. Para o filósofo:

Uma sociedade pode estar na civilização do mais alto desenvolvimento tecnológico, mas se as pessoas se encontram atrasadas de um modo peculiarmente disforme em relação à sua própria civilização, e não apenas por terem em sua arrasadora maioria experimentado a formação nos termos correspondentes ao conceito de civilização, mas também por se encontrarem tomadas por uma agressividade primitiva, um ódio primitivo, ou na terminologia culta, um impulso de destruição, que contribui para aumentar ainda mais o perigo de que toda esta civilização venha a explodir, aliás a uma tendência imanente que a caracteriza (ADORNO, 1995, p.155). 
As leis legitimam a convivência com o outro em ambientes sociais, porém não garantem a superação de barreiras atitudinais, nessa perspectiva todos precisam se comprometer com o acolhimento das diferenças em nossa sociedade e escolas.

Um dos princípios orientadores da educação técnica profissional de nível médio, segundo as Diretrizes Curriculares Nacionais (Res. 6/2012), é o reconhecimento dos sujeitos em suas diversidades, considerando, entre outros, os estudantes público-alvo da educação especial.

Independentemente do nível ou modalidade de ensino que o estudante público-alvo da educação especial se encontre, esse sujeito/estudante tem direito a aprender, por mais desafiador que seja, pois, como questiona Adorno (1995), "[...] é de perguntar de onde alguém se considera no direito de decidir a respeito da orientação da educação dos outros" (p.141).

Quando se recusa a discutir o direito do outro de aprender, retira-se desse sujeito o direito de se emancipar, de sair de sua menoridade, de ser cidadão de fato. $O$ discurso conservador contribui para o círculo vicioso da reprodução da desigualdade social e educacional. Damasceno (2006) contribui ao debate quando nos leva a refletir que:

[...] o professor que puder libertar-se das dificuldades por ele mesmo impostas ao processo de acolhimento aos estudantes deficientes, poderá se tornar aquilo que chamamos de agente agregador, ou seja, um multiplicador de ideias e reflexões que também poderão apontar para a libertação de outras consciências, que se encontram encarceradas pela auto inculpável menoridade (p. 45).

Damasceno (2006, p. 29), assinala que “[...] somos capazes de criar condições em espaços de formação que estimulem o desenvolvimento da sensibilidade nos professores" para que os mesmos compreendam que a inclusão em educação se trata de um movimento pautado em variadas políticas públicas educacionais. Portanto, discorrer que a inclusão é um modismo é um equívoco, visto toda a legitimidade que o movimento possui.

Outra questão apontada pelos sujeitos de nosso estudo, referente à inclusão em educação dos estudantes público-alvo da educação especial, é a falta de acessibilidade no Campus em alguns âmbitos. As narrativas alegam questões orçamentárias, assim como afirmam que o projeto inicial do Campus não previu a acessibilidade arquitetônica. Para que o Campus atenda às normas de acessibilidade é preciso passar por uma reforma.

De forma sintética, o participante descreve a situação que o Campus vive em relação à inclusão de pessoas com deficiência, e aponta os aspectos que precisam melhorar. Os agentes pesquisados reconhecem que é preciso fortalecer as discussões sobre inclusão no Campus para garantir o bom atendimento.

Ainda é muito incipiente. Eu sei que a gente não se fortaleceu o suficiente para garantir via departamento pedagógico, via assessoria, um olhar mais aprofundado disso. Eu acho que ainda falta mais estudo, falta mais prioridade para isso; e aí a gente sabe que pela conjuntura do que significa um Instituto Federal, as demandas que têm, infelizmente, às vezes o tempo também é um fator impeditivo (P6).

Além da precariedade na acessibilidade arquitetônica, foi citado também pelos participantes da pesquisa a falta de acessibilidade comunicacional e atitudinal, pontos críticos que a equipe do NAPNE vem trabalhando para melhorar. 


\section{CONSIDERAÇÕES FINAIS:}

Esta pesquisa debateu sobre políticas públicas de inclusão em educação e os desafios à escolarização profissional do público-alvo da educação especial no IFRR (Instituto Federal de Roraima). Diferentes apreensões puderam ser observadas sobre o processo da inclusão em educação na educação profissional. Ter a oportunidade de investigar como as políticas de inclusão em educação são postas em ação no IFRR/CBV para atender aos estudantes públicoalvo da educação especial foi importante para compreender como se dá a interface entre essas duas modalidades de ensino.

Não se pode deixar de reconhecer os avanços da inclusão em educação, com o aumento do número de matrículas de pessoas com deficiência nos sistemas regulares de ensino. Esse feito deve-se ao chamado movimento mundial em prol da inclusão, que mobilizou pessoas de todas as esferas sociais com o objetivo de dar voz e vida aos excluídos. Podemos considerar que surtiu efeito. Prova disso são os inúmeros dispositivos legais que foram formulados da década de 1990 aos dias atuais, outorgando às minorias, entre elas as pessoas com deficiência, o direito de participar da vida social como pessoa livre, para decidir o caminho que deseja seguir na vida.

Retomando as questões de estudo, que serviram de base para essa pesquisa, os resultados apontaram que:

Acessibilidade atitudinal - quanto a esse item, ele foi bem citado pelos gestores, participantes da pesquisa, como algo que ainda não foi superado, ainda há no campus barreiras que precisam ser eliminadas, citadas ainda como sendo um dos maiores desafios.

Acessibilidade arquitetônica - a instituição reconhece que precisa prover e ainda não tem como dar conta; alega que dentro das possibilidades da instituição procura atender aos estudantes, mas tem consciência de que há muito a caminhar nesse sentido. Ainda há prédios sem rampas e sem elevadores, restringindo o acesso do estudante público-alvo da educação especial em todos os ambientes do Campus.

Acessibilidade comunicacional - quanto a esse item, foi citado por um dos gestores que o IFRR precisa melhorar em relação à comunicação, torná-la mais acessível. Fixar os informes de forma a atender a todas as pessoas em suas particularidades: em uma altura que atenda à pessoa que faz uso de cadeiras de rodas; colocar na escrita braile para os estudantes com deficiência visual; caso sejam colocadas nos informes alguma sigla, especificar, para que fique claro para a pessoa com deficiência auditiva; entre outras formas de tornar acessível a informação.

Acessibilidade metodológica - o professor é assessorado pelo NAPNE e pelo Departamento de Ensino sobre como adequar sua metodologia às particularidades dos estudantes. Tanto a equipe do NAPNE, quanto a equipe pedagógica buscam respaldo na organização didática, que instrui como deve se organizar o ensino e os meios que facilitem a aprendizagem dos estudantes. Ficou claro o empenho do NAPNE para desempenhar bem seu papel dentro da instituição.

Acessibilidade instrumental - para atender esse item, o NAPNE assessora professores e estudantes no uso dos recursos didáticos. O NAPNE está equipado de material para atender aos estudantes público-alvo da educação especial, segundo relatos dos participantes da pesquisa. a maior parte dos equipamentos é para atender pessoas com deficiência visual, mas pouco se faz uso desse material por não ter no NAPNE pessoa com preparo para manusear tais equipamentos.

Acessibilidade programática - diz respeito à detecção e eliminação de barreiras invisíveis existentes nas políticas, normas, portarias, leis e outros instrumentos afins. Não foi citado sobre a existência de uma comissão permanente responsável para fazer esse trabalho. Quem se mostrou 
atento a essa questão foi a equipe do NAPNE, que precisa estar atualizada sobre as políticas de inclusão.

As políticas de inclusão estão centradas no acesso para ingresso nos cursos ofertados pelo o IFRR, que é dado por meio de edital, respeitando o princípio da igualdade e da equidade. Garante o intérprete de Libras (Língua Brasileira de Sinais) nas salas de aula que tenha aluno com deficiência auditiva/surdez. Dá vida a uma ação realizada por dois professores da instituição: trabalhar o letramento e os fundamentos da matemática com alunos com deficiência auditiva/surdez, com o objetivo de que esses estudantes acompanhem o conteúdo em sala de aula sem perdas na aprendizagem.

O NAPNE se encarrega de ofertar oficinas para os alunos que têm interesse em aprender Libras, com o objetivo de disseminar o uso da língua de sinais e facilitar a comunicação entre pessoas com e sem deficiência auditiva.

Sobre os fatores que interferem no desenvolvimento de práticas pedagógicas inclusivas, as entrevistas realizadas com os participantes mostraram que são diversos. Tais como a escassez de profissionais para trabalhar com o público em questão, a falha na acessibilidade em vários âmbitos, a pouca clareza do papel do NAPNE na instituição, e, principalmente, a falta de uma participação mais efetiva por parte dos docentes no que diz respeito às questões da educação especial na perspectiva inclusiva.

A presente pesquisa mostrou que são diversos os desafios para a implementação da educação especial na perspectiva inclusiva. A inserção de estudantes com deficiência no ensino técnico profissionalizante é uma realidade. Eles estão lá, ainda em fase de adaptação, porque ainda encontram barreiras que precisam ser superadas.

A educação como direito de todos possui o dever de possibilitar oportunidades de ensino e aprendizagem se adequando às reais condições de cada estudante. Dessa forma, os espaços educacionais necessitam organizar-se na perspectiva do acolhimento da demanda diversificada, respeitando e criando possibilidades (no sentido da equidade) para que possamos conviver com as diferenças, e, sobretudo, reconhecer sua riqueza.

\section{REFERÊNCIAS}

ADORNO, Theodor Ludwig Wiesengrund. Educação e emancipação. Tradução Wolfgang Leo Maar. Rio de Janeiro: Paz e Terra, 1995.

BRASIL. Política Nacional de Educação Especial na perspectiva da Educação Inclusiva. Brasília: MEC/SEESP, 2008.

BRASIL. Ministério da Educação - Diretrizes Curriculares para Educação Profissional de nível médio, 2012.

BRASIL. Lei n. 13.146 de 06 de julho de 2015. Institui a Lei Brasileira de Inclusão da Pessoa com Deficiência (Estatuto da Pessoa com Deficiência). Disponível em http://www.planalto.gov.br/ccivil_03/_ato2015-2018/2015/lei/113146.htm. Acesso em mar. 2020.

BRASIL. Ministério da Educação. Censo da Educação Básica 2019 - Notas Estatísticas. Brasília.

Disponível em

http://portal.inep.gov.br/censo-escolar. Acesso em mar. 2020 
BRASIL. Ministério da Educação/Secretaria de Educação Tecnológica/Instituto Federal de Educação, Ciência e Tecnologia de Roraima - IFRR. Portaria de 08 de novembro de 2006 - n. 569/2006. Designa servidores para comporem o Núcleo de Apoio e Inclusão Profissional às Pessoas com Necessidades Educacionais Especiais - NAPNE - Boa Vista - RR.

BRASIL. Ministério da Educação/Secretaria de Educação Tecnológica - Conselho Superior/ Instituto Federal de Educação, Ciência e Tecnologia de Roraima - IFRR. Organização Didática. Boa Vista - RR. 2018.

BRASIL. Ministério da Educação/Secretaria de Educação Tecnológica - Conselho Superior/Instituto Federal de Educação, Ciência e Tecnologia de Roraima - IFRR. Plano de Desenvolvimento Institucional. Boa Vista - RR. 2014-2018.

DAMASCENO, Allan Rocha. A formação dos professores e os desafios para a educação inclusiva: as experiências da escola Municipal Leônidas Sobrino Pôrto. Dissertação (Mestrado em Educação). Programa de Pós-Graduação Stricto Sensu em Educação, Universidade Federal Fluminense (UFF), Rio de Janeiro, 2006.

FRIGOTTO, Gaudêncio. A relação da educação profissional e tecnológica com a universalização da educação básica. Educ. Soc., Campinas, v. 28, n. 100 - Especial, p. 1129-1152, out. 2007.

LIBÂNEO, José Carlos; OLIVEIRA, João Ferreira de e TOSCHI, Mirza Seabra. Educação escolar: políticas, estrutura e organização. 10 ed. São Paulo: Cortez, 2012. (coleção docência em formação: saberes pedagógicos / coordenação Selma Garrido Pimenta).

PACHECO, Elieser (Org.) Institutos Federais - uma revolução na educação profissional e tecnológica. Brasília: Moderna, 2011.

PIETRO, Rosângela Gavioli. Atendimento escolar de alunos com necessidades educacionais especiais: um olhar sobre as políticas públicas de educação no Brasil. In: VALÉRIA. Amorim Arantes. Inclusão escolar. São Paulo: Summus, 2006, p. 31-73.

TOMAZI, Gustavo Machado. Competência, qualificação - o correto? In: MANTOAN, Maria Teresa Eglér. Para uma escola do século XXI. Campinas/SP: Biblioteca/UNICAMP, 2013. p. 49-51.

\section{Informações das autoras}

Maria Leilza Pires Siqueira

Universidade Federal Rural do Rio de Janeiro

E-mail: marialeilza@gmail.com

ORCID: https://orcid.org/0000-0001-5171-831X

Link Lattes: http://lattes.cnpq.br/6693334159226599

Patrícia Ferreira de Andrade

Universidade Federal Rural do Rio de Janeiro

E-mail: pat.fandrade@gmail.com

ORCID: https://orcid.org/0000-0002-8878-1395

Link Lattes: http://lattes.cnpq.br/5302548383203187 
Allan Rocha Damasceno

Universidade Federal Rural do Rio de Janeiro

E-mail: lepedi-ufrri@hotmail.com

ORCID: https://orcid.org/0000-0003-0577-805X

Link Lattes: http://lattes.cnpq.br/0177717397152120 